\title{
USAGE OF PALM OIL, PALM KERNEL OIL AND THEIR FRACTIONS AS CONFECTIONERY FATS
}

\author{
NORAZURA AILA MOHD HASSIM* and NOOR LIDA HABI MAT DIAN*
}

\begin{abstract}
Palm oil, palm kernel oil and their fractions are currently being used globally in food products because of their versatility and cost-effectiveness. They are widely used in various food applications such as cooking oils, margarines, shortenings and vanaspati. In addition, they are vastly utilised in the confectionery industry especially in the chocolate confectionery. Due to the high price and inconsistent supply of cocoa butter, palm oil, palm kernel oil and their fractions have been used to produce cocoa butter alternatives (CBA) namely; cocoa butter equivalent (CBE), cocoa butter replacer (CBR) and cocoa butter substitutes (CBS) in which each one has its own strength for different confectionery applications. Technological developments in fractionation, interesterification and hydrogenation have brought palm oil, palm kernel oil and their fractions to a higher level of usage in the chocolate confectionery industry. Compilation of studies have shown that $C B E, C B R$ and $C B S$ can be produced from various technological paths to obtain the desired requirements. In addition, palm oil and its fractions are also suitable for other confectionery applications such as soft chocolate, chocolate syrup, ice cream coating and confectionery filling.
\end{abstract}

Keywords: palm fractions, cocoa butter equivalent (CBE), cocoa butter replacer (CBR), cocoa butter substitutes (CBS), confectionery fats.

Date received: 13 March 2017; Sent for Revision: 14 March 2017; Received in Final Form: 30 April 2017; Accepted: 4 July 2017.

\section{INTRODUCTION}

Chocolate is a type of confectionery which is popular due to its taste, aroma and texture as well as its nutritional attribute. Chocolate is recognised as a comfort food which provides pleasure and is craved when people are in stress or during low spirit (Macdiarmid and Hetherington, 1995). In America, chocolate has persistently turned out to be one of the foods that is craved (Firmin et al., 2016; Jáuregui-Lobera et al., 2012). The properties of chocolate confectionery are mainly influenced by the fat component used in chocolate.

Chocolate is a suspension of cocoa solids and sugar in a continuous fat phase. In general, the

\footnotetext{
* Malaysian Palm Oil Board,

6 Persiaran Institusi, Bandar Baru Bangi,

43000 Kajang, Selangor, Malaysia.

E-mail: azuraaila@mpob.gov.my
}

typical content of fat in chocolate confectionery is around $26 \%-35 \%$ of the formulation. Chocolate confectionery fats need to be snappable at $20^{\circ} \mathrm{C}$ in which this can be obtained through having sufficient crystalline fat. The fats are also characterised by their steep melting profile in order for the chocolate to melt completely in the mouth. The melting profile is usually between $30^{\circ} \mathrm{C}-35^{\circ} \mathrm{C}$ (Timms, 2003).

Chocolate has traditionally been made using cocoa butter (CB). $\mathrm{CB}$ is expensive as cocoa trees are cultivated in a few countries only such as Ivory Coast, Ghana, Indonesia and Brazil. Efforts have been made to find alternatives to $\mathrm{CB}$ and to replace parts of $\mathrm{CB}$ in chocolate, for economic and technological reason (Samsudin and Rahim, 1996; Lipp and Anklam, 1998; Borhan et al., 2011; Idris and Mat Dian, 2005). Thus, some manufacturers try to find cheaper alternative fats that are not derived from animal or synthetic fat, and yet have similar properties with that of $\mathrm{CB}$ in order to 
produce chocolate confectionery. Chocolates having more than $5 \%$ of other vegetable fats in the whole formulation are called 'compound chocolate'. In this connection, palm oil, palm kernel oil and their fractions can be used as alternative vegetable fats to make the 'compound chocolate'. Palm oil, palm kernel oil and their fractions are the choice of preference by the food manufacturers mostly due to their versatility, cost-effectiveness and nutritional benefits (Ong and Goh, 2002). The alternative vegetable fats or cocoa butter alternatives (CBA) can be categorised into three main types which are the cocoa butter equivalent (CBE), cocoa butter replacer (CBR) and cocoa butter substitute (CBS). Apart from the CBE, CBR and CBS, vegetable oils such as palm oil, palm olein and red palm olein can also be used for the production of soft chocolate. Figure 1 shows the processing flow chart of the refining and fractionation of palm oil and palm kernel oil as raw materials of CBE, CBR and CBS and soft chocolate. Figure 2 shows the common types of confectionery fats for the production of $\mathrm{CBE}, \mathrm{CBR}$ and $\mathrm{CBS}$.

\section{COCOA BUTTER EQUIVALENT}

CBE is a vegetable fat that has similar physical and chemical properties of CB (Smith, 2001). CBE can be formulated from other vegetable oil sources having similar triglycerides with $\mathrm{CB}$. The main fatty acids in CBE are the palmitic, stearic and oleic. The primary triacylglycerols (TAG) composition of CBE are the 1,3-dipalmitoyl-2-oleoyl glycerol (POP), 1(3)-stearoyl-2-oleoyl-3(1)-palmitoyl glycerol (POSt) and disaturated 1,3-distearoyl-2-oleoyl glycerol (StOSt). About $70 \%$ of the total TAG in CBE are from the POP, POSt and StOSt (Gunstone et al., 1992). In view that POP, POSt and StOSt are the prime TAG in $\mathrm{CBE}$, they influence the texture and taste of the chocolate through crystallisation and polymorphism (Afoakwa, 2016).

CBE has full compatibility with $\mathrm{CB}$, having similar chemical and physical properties (Minifie, 2012). CBE has an excellent flavour release, mouth feel, 'snap' texture and gloss. CBE also has good oxidative stability (Pease, 1985). However, in the European Union (EU), there is a limit for the amount of CBE permitted in chocolate formulations. The EU only permits a maximum of 5\% CBE for the product to be labelled as chocolate. Full replacement of $\mathrm{CB}$ with $\mathrm{CBE}$ is possible in many countries including the EU, provided suitable labelling such as 'supercoating' or 'coating' is given (Talbot, 2007).

Palm mid-fraction (PMF) which is rich in POP has been used as blends with other vegetable fats rich in SOS and POS TAG such as illipe, shea, sal, mango kernel and kokum to produce CBE (Talbot, 2007; Bootello et al., 2012). Many studies showed

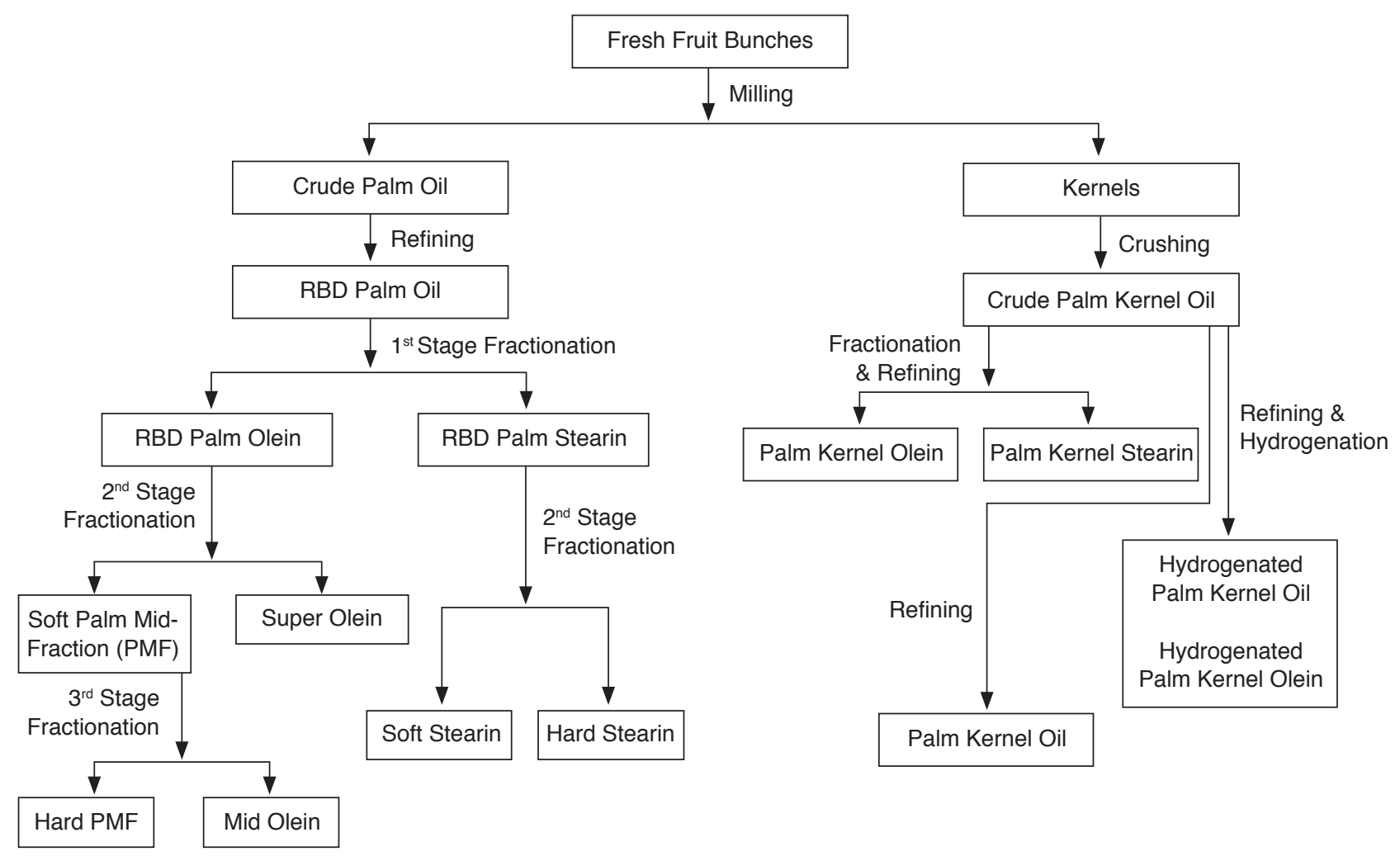

Source: MPOB (2009); Kellens et al. (2007).

Figure 1. Processing of palm oil, palm kernel oil and their fractions for confectionery fats. 


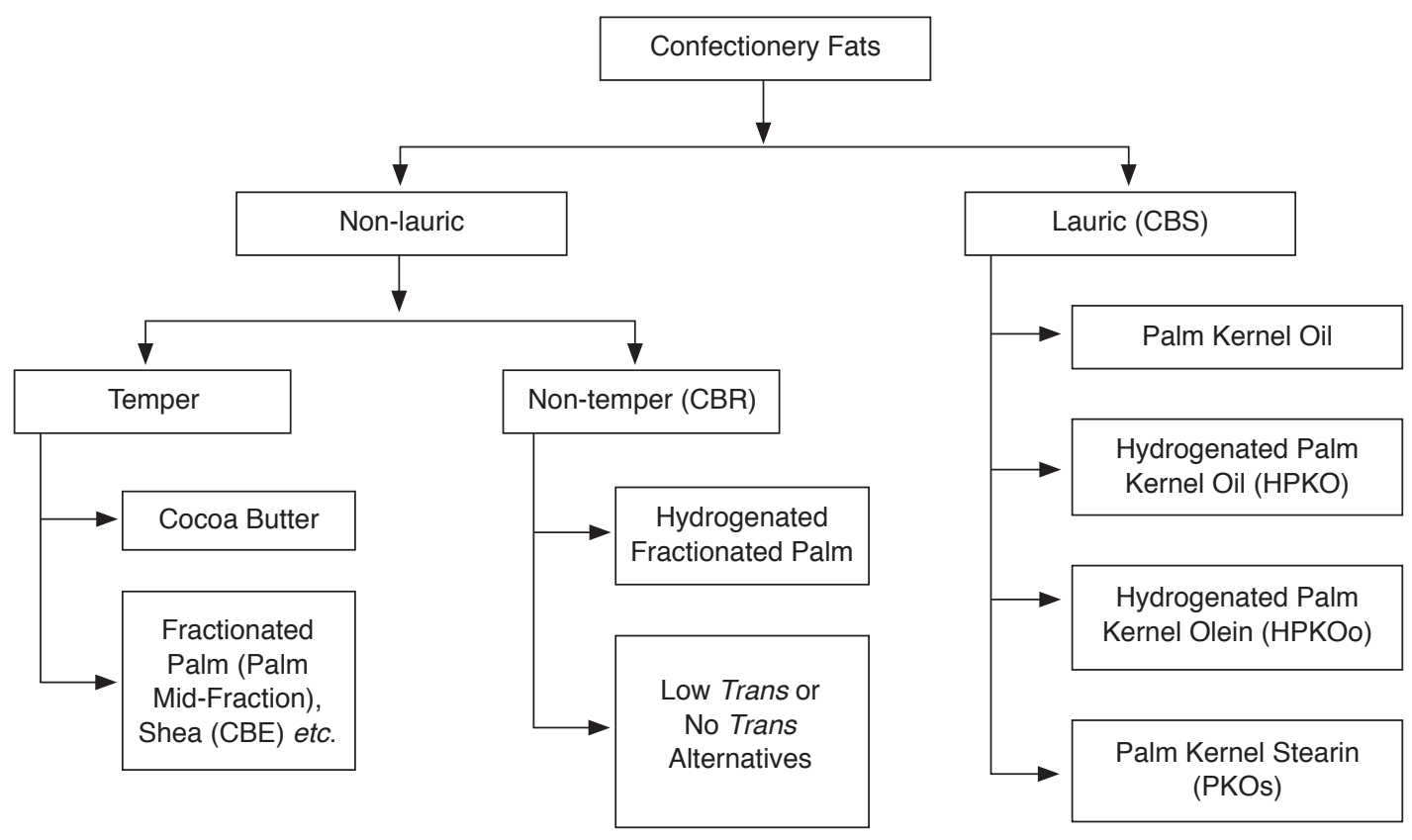

Source: MPOB (2009); Talbot (2007).

Figure 2. Typical confectionery fats group.

blends of PMF with mango kernel fat to produce CBE (Jun et al., 2016; Sonwai et al., 2014; Elham et al., 2013). Sonwai et al. (2014) found that PMF/ mango kernel oil blend of 20/80 based on weight percentage provides the best crystallisation, slip melting point and melting behaviour with CB. In addition, Nesaretnam and Mohd Ali (1992) found that Shorea macrophylla species of illipe provided the best compatibility with PMF as CBE. Table 1 shows TAG composition of the most common fats used for CBE formulation. Table 2 compares the TAG composition of $\mathrm{CB}$ and $\mathrm{CBE}$.

PMF is a sharp-melting fat and is produced through further fractionation of palm olein (Gee, 2007). PMF can be produced through solvent (hexane or acetone) or dry fractionation. There was also development in combining both dry and

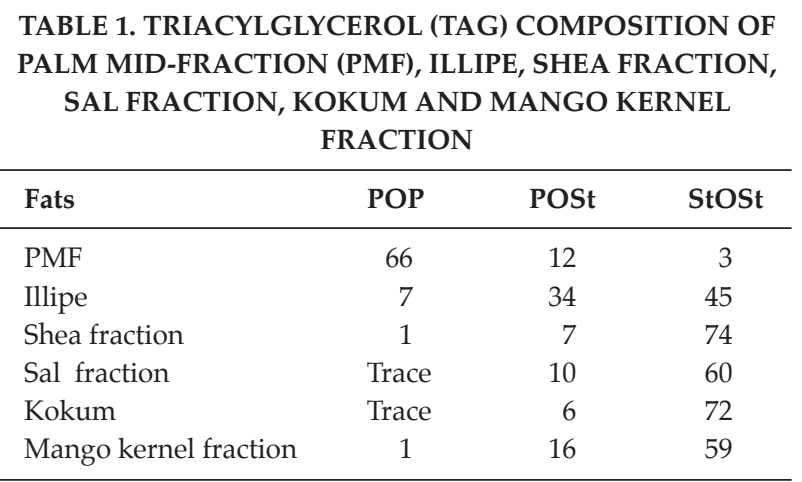

Note: POP - 1, 3-dipalmitoyl-2-oleoyl glycerol. POSt - 1, (3)-stearoyl-2-oleoyl-3(1)-palmitoyl glycerol. StOSt - 1, 3-distearoyl-2-oleoyl glycerol.

Source: Talbot (2007). solvent fractionations as described by Hashimoto et al. (2001). Hard PMF from combined fractionation was found to have better quality compared to solvent or dry fractionated PMF in terms of melting curves and snapping qualities. For the production of CBE, few types of PMF are available as shown in Figure 1. These PMF are classified based on their iodine values (IV). The harder PMF (with lower IV) are more enriched with POP content. PMF does not provide waxy taste, has good oxidative stability as it contains low level of linoleic acid and is free from trans-fatty acid (Samsudin et al., 1996). However, Wong (1991) reported that PMF with IV 46-55 are not suitable for CBE application as these PMF are too soft which resulted in undesirable solid fat content profiles. It is also reported that a PMF having waxy and tailing solid fat content characteristics at

\section{TABLE 2. TRIACYLGLYCEROL (TAG) COMPOSITION OF COCOA BUTTER AND COCOA BUTTER EQUIVALENT (CBE)}

\begin{tabular}{lccc}
\hline Fats & POP & POSt & StOSt \\
\hline Cocoa butter $^{\mathrm{a}}$ (Malaysia) & 15.0 & 35.0 & 25.0 \\
Cocoa butter $^{\mathrm{b}}$ (Malaysia) & 15.1 & 40.4 & 31.0 \\
Cocoa butter $^{\mathrm{b}}$ (Ivory Coast) & 15.2 & 39.0 & 27.1 \\
Cocoa butter $^{\mathrm{b}}$ (Ghana) & 15.3 & 40.1 & 27.5 \\
Cocoa butter $^{\mathrm{b}}$ (Nigeria) & 15.5 & 40.5 & 28.8 \\
Cocoa butter $^{\mathrm{b}}$ (Brazil) & 13.6 & 33.7 & 23.8 \\
CBE $^{\mathrm{a}}$ & 30.0 & 20.0 & 25.0 \\
\hline
\end{tabular}

Note: POP - 1, 3-dipalmitoyl-2-oleoyl glycerol. POSt - 1, (3)-stearoyl-2-oleoyl-3(1)-palmitoyl glycerol. StOSt - 1, 3-distearoyl-2-oleoyl glycerol.

Source: a Idris et al. (1995); b Shukla (2005). 
$40^{\circ} \mathrm{C}$ can occur if POP in enriched together with tripalmitin (PPP). Characteristics of hard and soft PMF are shown in Tables 3 and 4.

Due to inconsistencies in supply of illipe and shea butter (as both fats are categorised as wild crop), Samsudin and Rahim (1996) embarked on a study to use PMF without blends with other vegetable fats to produce white chocolate/chocolate pastel. The study found that the chocolate made from 100\% PMF is resistant to bloom up until 12 weeks, which is comparable with white chocolate formulated using CB. In addition, the study also found that the PMF has lower tempering temperature compared to $\mathrm{CB}$. Bootello et al. (2012; 2013) studied the blend of PMF with high oleic-high stearic sunflower hard stearins and blend of PMF with sunflower hard stearin, respectively. Both studies found that PMF blended with both fractions of sunflower oil met all of the requirements as CBE. Apart from PMF, the study by Kang et al. (2003) had found that the solid fraction of soft stearin produced through a two-stage acetone fractionation has no PPP content but contains vast amount of symmetrical monounsaturated TAG (e.g. POP). It has characteristics quite similar to PMF used for the production of CBE. At body temperature, PPP as reported by Idris and Mat Sahri (2007), will not provide complete melting. Kang et al. (2013) found that the blending of the solid fraction of soft stearin with shea stearin at a ratio of 40:60 (\% weight)

TABLE 3. VARIOUS QUALITIES OF HARD PALM MID-FRACTION (HPMF) TO PRODUCE COCOA BUTTER EQUIVALENT (CBE)

\begin{tabular}{lccc}
\hline Type of HPMF & IV & $\begin{array}{c}\text { POP content } \\
(\%)\end{array}$ & $\begin{array}{c}\text { SFC (\% max) } \\
\text { at } 35^{\circ} \mathbf{C}\end{array}$ \\
\hline HPMF 1 & $28-30$ & $>80$ & 6 \\
HPMF 2 & $32-35$ & $>70$ & $3-6$ \\
HPMF 3 & $35-37$ & $>60$ & $2-5$ \\
HPMF 4 & $37-40$ & $>50$ & $1-4$ \\
\hline
\end{tabular}

Note: IV - iodine value.

POP - 1, 3-dipalmitoyl-2-oleoyl glycerol.

$\mathrm{SFC}$ - solid fat content.

Source: Kellens et al. (2007).

TABLE 4. CHARACTERISTICS OF SOFT AND HARD PALM MID-FRACTIONS (PMF)

\begin{tabular}{lcc}
\hline Parameter & PMF 1 (soft PMF) & PMF 2 (hard PMF) \\
\hline Iodine value & $42-46$ & $32-36$ \\
SFC $(\%)$ & & \\
At $10^{\circ} \mathrm{C}$ & 75 & 95 \\
At $20^{\circ} \mathrm{C}$ & 45 & 90 \\
At $30^{\circ} \mathrm{C}$ & 0 & 47.0 \\
At $35^{\circ} \mathrm{C}$ & - & 6 \\
At $40^{\circ} \mathrm{C}$ & - & 0 \\
\hline
\end{tabular}

Note: SFC - solid fat content.

Source: Deffence (1995). was found to be suitable as CBE. This CBE blend is compatible with $\mathrm{CB}$ at a ratio of 3:7 without greatly changing its physical propertis, which include enthaphies, melting/cryastallisation and solid fat contents. In addition, Kellens et al. (2007) reported that palm mid stearin can be utilised as CB extender but with limited application.

In recent years, enzymatic modification of oils and fats has been the focus and attention to produce specific TAG for the production of CBE. Lipase catalysed interesterification of palm oil has been the centre of attraction of many studies in view that palm oil is perceived as important for the production of CBE (Undurraga et al., 2001; Abigor et al., 2003). Mohamed (2013) confirmed that $\mathrm{CBE}$ could be produced through TAG's restructuring of PMF. The study was done through the reaction of enzymatic acidolysis of refined PMF with palmitic and stearic fatty acid mixtures. Another example is the production of $\mathrm{CBE}$ using the lipase catalysed interesterification of refined, bleached and deodorised palm oil (RBD PO) with hydrogenated soyabean oil (HSO) (Abigor et al., 2003). Apart from this, Undurraga et al. (2001) also conducted a study on the production of CBE through enzymatic interesterification of PMF using stearic acid in a solvent-free system in which Novo lipase Lipozyme ${ }^{\mathrm{TM}}$ was used as a catalyst. TAG composition of interesterified palm olein using three procedures of solvent fractionation is shown in Table 5. Typical milk chocolate formulation using hard PMF and CBE is shown in Table 6. All of the ingredients are mixed, refined, conched, tempered, moulded and cooled to produce milk chocolate before product storage.

\section{COCOA BUTTER REPLACER}

CBR is another alternative to $\mathrm{CB}$ and was traditionally produced through selective partial hydrogenation of liquid oils (e.g. palm olein, soyabean oil, cottonseed and rapeseed oil) using nickel catalysts with promoting agents (e.g. sulphides) alone or followed by fractionation. Palm olein of IV equal to or greater than 68 would be able to produce good quality high trans CBR. Such oils would have most PPP and PPO/POP TAG removed through a good fractionation process (Wong, 1991). CBR does not need tempering as it would be able to form stable $\beta^{\prime}$ polymorph easily through simple cooling (Timms, 2003; Minifie, 2012). Partially hydrogenated CBR has poor flavour release, mouth feel and 'snap' texture. However, it has fair gloss, good oxidative stability and is inexpensive. Taking into account of these qualities, partially hydrogenated CBR is categorised as low quality CBR. Partially hydrogenated and fractionated CBR, on the other hand, has good flavour release, 
TABLE 5. TRIACYLGLYCEROL (TAG) COMPOSITION OF INTERESTERIFIED PALM OLEIN (IE POo) USING THREE PROCEDURES (A, B and C) OF SOLVENT FRACTIONATION

\begin{tabular}{lccc}
\hline \multirow{2}{*}{ Fraction } & \multicolumn{3}{c}{ TAG (\%) } \\
\cline { 2 - 4 } TAG/IE POo & POP & POSt & StOSt \\
\hline F2(A) & 15.3 & 44.1 & 29.6 \\
F2(B) & 16.0 & 38.7 & 23.1 \\
F2(C) & 13.7 & 38.5 & 24.8 \\
Cocoa butter & 18.9 & 41.3 & 29.7 \\
\hline
\end{tabular}

Note: POP - 1, 3-dipalmitoyl-2-oleoyl glycerol. POSt - 1, (3)-stearoyl-2-oleoyl-3(1)-palmitoyl glycerol. StOSt - 1, 3-distearoyl-2-oleoyl glycerol. Source: Idris et al. (2005) [Reproduced from American Oil Chemist's Society (AOCS)].

TABLE 6. GENERAL COMPOUND MILK CHOCOLATE FORMULATION USING HARD PALM MID-FRACTION (PMF) OR COCOA BUTTER EQUIVALENT (CBE)

\begin{tabular}{lcc}
\hline Ingredients & Using Hard PMF & Using CBE \\
\hline Cocoa mass & 15 & 12 \\
Hard PMF & 22 & - \\
CBE & - & 22 \\
Whole milk powder & 17 & 20 \\
Sugar & 46 & 46 \\
Lecithin & 0.4 & 0.4 \\
Salt & - & 0.03 \\
Vanillin & 0.03 & 0.015 \\
Fat content & $34 \%$ & $33-34 \%$ \\
\hline
\end{tabular}

Source: Wong (1991); Hashimoto et al. (2001).

gloss and oxidative stability. However, it has only fair mouth release and 'snap' texture (Pease, 1985). By fractionating the hydrogenated CBR, solid fat content can be increased (Wong, 1991; Timms, 2003).

As CBR has similar physical properties but having different TAG from $C B$, it has less compatibility with CB. CBR is normally used as a compound for coatings. The process of partial hydrogenation produces trans-fatty acids, which gives a negative impact to health and among others, a higher risk in developing coronary heart disease. The partially hydrogenated CBR commonly found in the markets has as much as $46 \%$ of trans-fatty acid (Table 7). In view of this, the World Health Organisation (WHO) and the US Food and Drugs Administration (FDA) had called for the elimination of trans-fat in all food production. Many countries followed the WHO and FDA's regulations to restrict production of trans-fatty acid and made it mandatory for trans-fatty acid labelling in foods (Uauy et al., 2009; Downs et al., 2013). Due to this development, manufacturers are pushed to produce CBR with low or zero trans-fatty acid. Many confectionery companies have been able to manufacture low and
TABLE 7. COMPARISON OF FATTY ACIDS IN COCOA

BUTTER AND HIGH-TRANS COCOA BUTTER REPLACER (CBR)

\begin{tabular}{lcc}
\hline Fatty acid & $\begin{array}{c}\text { Cocoa butter } \\
(\boldsymbol{\%})\end{array}$ & $\begin{array}{c}\text { High-trans CBR } \\
\mathbf{( \% )}\end{array}$ \\
\hline C16:0 & 26 & 23 \\
C18:0 & 32 & 12 \\
C18:1 cis & 34 & 16 \\
C18:1 trans & 0 & 46 \\
\hline
\end{tabular}

Source: Hossain (2013).

zero trans CBR using palm oil fractions such as $\mathrm{PPO}$ with specific fractionation conditions (Smith, 2012).

Kellens et al. (2007) has well reviewed the applications of palm stearin. They reported that palm stearin is suitable for hard coating. In addition, they have also reported that mid stearin can be utilised as coatings but with limited application. Ramli et al. (2014) had studied the physico-chemical properties of PMF, palm stearin and olive oil blend in which the blend was found to exhibit better oxidative stability and may be suitable as a CB alternative. A study by Jahurul et al. (2014) blended palm stearin with mango seed to produce CBR without transfatty acid. The study found that this CBR blend could overcome tempering challenges especially in tropical countries. Earlier study by Zaidul et al. (2007) found that palm kernel oil (PKO) is suitable for CBR when it is fractionated with supercritical carbon dioxide and then blended with other oils such as palm oil and commercial stearic and oleic fatty acids. This method produces CBR with lower lauric and myristic acids.

\section{COCOA BUTTER SUBSTITUTES}

CBS are alternative vegetable fats that have similar physical properties with CB. However, the fats consist of high lauric acid and therefore have the least compatibility and tolerance with $\mathrm{CB}$. These CBS are also known as lauric CBS. The main sources of lauric CBS are palm kernel oil and coconut oil. Similar to CBR, lauric CBS does not need tempering, as through simple cooling, it is able to form stable crystal form of $\beta^{\prime}$ (Timms, 2003; Minifie, 2012). Lauric CBS is mainly used as a compound for moulded products and coatings.

Lauric CBS can be prepared using fractionation and interesterification modification techniques. The simplest CBS are palm kernel stearin and hydrogenated palm kernel oil. The preparation of CBS via traditional fractionation of palm kernel oil will normally follow with full hydrogenation to obtain hardened CBS. The solid fat content profile of hydrogenated palm kernel oil and hydrogenated palm kernel stearin is shown in Figure 3. Fractionated CBS also has excellent flavour release, 


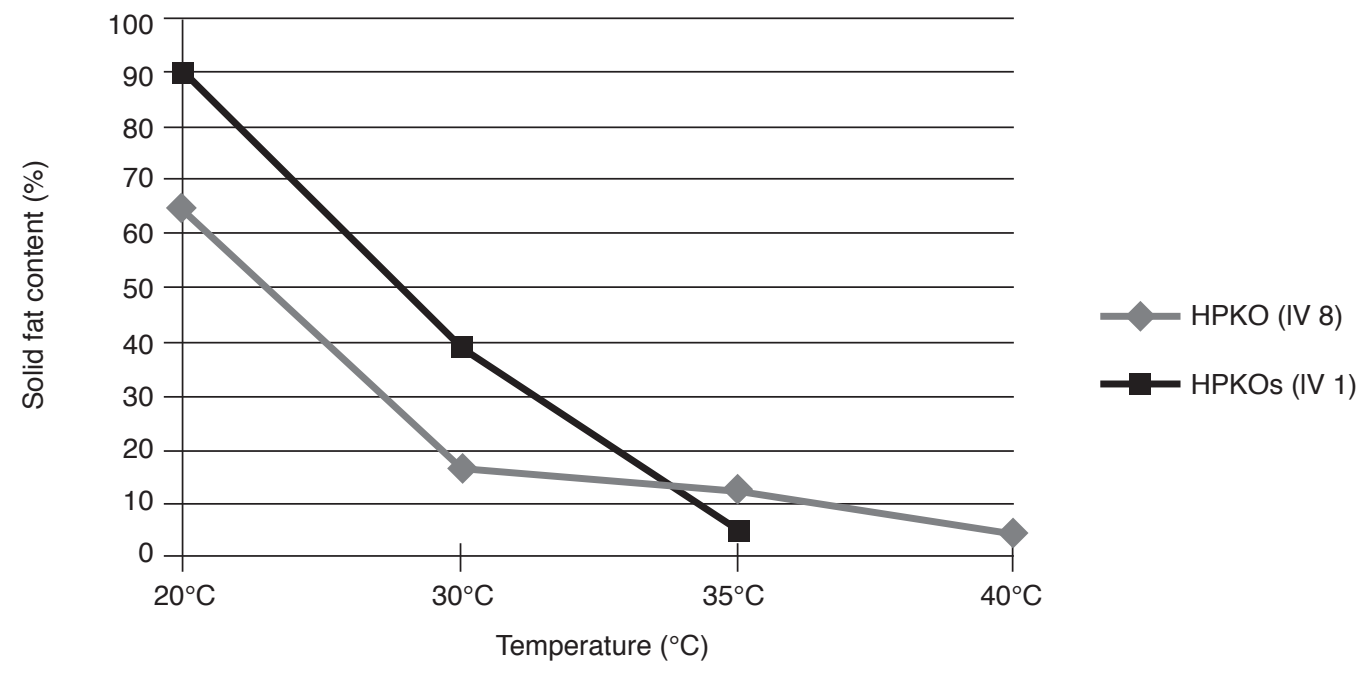

Source: MPOB (2009).

Figure 3. Solid fat content of hydrogenated palm kernel oil (HPKO) and hydrogenated palm kernel stearin (HPKOs).

mouth feel, 'snap' texture and oxidative stability. In addition, it provides good gloss (Shukla, 2005). However, a study by Calliauw et al. (2005) showed that high-quality CBS could be achieved with twostage static fractionation process of palm kernel oil. Earlier patent by Cain et al. (1995) showed that a non-hydrogenated, non-tempered lauric based hard coating fats could be obtained by blending $25 \%-55 \%$ of the first palm kernel stearin fraction (first fractionation of palm kernel fat) with $75 \%$ $45 \%$ of fractionated palm kernel stearin (double fractionated palm kernel fat). The blend of first and second fractionated palm kernel fat with $5 \%$ palm stearin showed good contraction and demoulding characteristics. Wong (1991) reported that low IV palm kernel stearin (PKS) of below 7.6 is needed to facilitate mould release. Table 8 shows characteristics of various cocoa butter substitutes.

A study by Norizzah et al. (2004) showed that chemical interesterification of palm stearin and palm kernel olein could be used to produce non-temper type of confectionery fats as it forms $\beta^{\prime}$-tending polymorphs with very fine spherulitic crystal network. Interesterified CBS has good flavour release, mouth feel, 'snap' texture and gloss. It also has excellent oxidative stability (Pease, 1985). Apart from that, Borhan et al. (2011) conducted a study to produce low calorie CBS in which specific fatty acids at positions 1 and 3 of the TAG were obtained through interesterification of PMF, palm kernel stearin and medium chain triglycerides (MCT). The study found that interesterified fat from palm oil is a bit softer compared to CB. Nonetheless, the interesterified fat from palm oil is comparable with CB in terms of other specifications such as slip melting point and solid fat content.

There is an emerging trend to limit the intake of trans-fat and saturated fats in foods due to the possible risk of cardiovascular diseases. A patent by Cruz (2015) claimed that they were able to produce CBS with $2 \%$ or less trans-fatty acid with $35 \%-60 \%$ of saturated fatty acid, $40 \%-65 \%$ unsaturated fatty acid, 30\%-55\% hydrogenated and interesterified fat and $6 \%$ or less fully hydrogenated fat. The patent

TABLE 8. CHARACTERISTICS OF VARIOUS COCOA BUTTER SUBSTITUTES (CBS)

\begin{tabular}{|c|c|c|c|c|c|}
\hline Characteristics & A & B & $\mathrm{C}$ & D & E \\
\hline Slip melting point $\left(\mathrm{SMP},{ }^{\circ} \mathrm{C}\right)$ & 34.5 & 33.5 & 32.0 & 34.5 & 35.5 \\
\hline Iodine value (IV) & 0.4 & 0.8 & 7.4 & 0.8 & 0.8 \\
\hline \multicolumn{6}{|l|}{ Solid fat content (SFC, \%) } \\
\hline $20^{\circ} \mathrm{C}$ & 94.4 & 94.6 & 80.3 & 93.3 & 93.7 \\
\hline $25^{\circ} \mathrm{C}$ & 87.0 & 86.7 & 64.9 & 83.7 & 84.2 \\
\hline $30^{\circ} \mathrm{C}$ & 48.9 & 48.5 & 33.2 & 48.9 & 48.4 \\
\hline $35^{\circ} \mathrm{C}$ & 4.8 & 4.5 & - & 6.5 & 6.4 \\
\hline $37.5^{\circ} \mathrm{C}$ & 1.2 & 1.8 & - & 2.8 & 2.3 \\
\hline $40^{\circ} \mathrm{C}$ & - & - & - & 1.3 & 0.3 \\
\hline
\end{tabular}

Note: Samples A and B: CBS from Malaysia. Sample C, D and E: imported CBS.

Source: Nesaretnam et al. (1990). 
uses vegetable oils which comprise of the following oils: sunflower, safflower, low erucic rapeseed, canola, soyabean, high oleic sunflower, high oleic safflower, high oleic rapeseed, high oleic canola, high oleic soyabean, coconut (hydrogenated and interesterified), palm fractions (single fat, fully hydrogenated and/or interesterified) and hybrid palm and olive. Table 9 shows the typical compound chocolate formulation using CBS.

TABLE 9. GENERAL COMPOUND CHOCOLATE FORMULATION USING COCOA BUTTER SUBSTITUTES (CBS)

\begin{tabular}{lrrr}
\hline Ingredients & A (\%) & B (\%) & C (\%) \\
\hline Cocoa powder (10/12) & 6 & 5 & 7 \\
CBS & 32 & 35 & 29 \\
Skim milk powder & 17 & 15 & 19 \\
Sugar & 45 & 45 & 44.7 \\
Lecithin & - & - & 0.3 \\
\hline Total & 100 & 100 & 100 \\
\hline
\end{tabular}

Source: $\quad$ MPOB (2009); Stewart et al. (2002);

Nesaretnam et al. (1990).

\section{OTHER MAIN CONFECTIONERY APPLICATIONS}

Apart from CBA, palm oil and its fractions can be utilised for other confectionery applications such as chocolate spread, chocolate syrup and ice cream coating. Traditionally, chocolate spread was formulated using partially hydrogenated soft oil which contained trans-fatty acid of between $0.7 \%$ $11.1 \%$ in the product (Shamsudin, 2004). Chocolate spread can be formulated using either palm oil, palm olein or red palm olein with other soft oils or butter fat (El-kalyoubi et al., 2011; El-Hadad et al., 2011). Chocolate spread can be divided into two categories: i) oil emulsion, or ii) water-in-oil emulsion for spread containing fat of less than $40 \%$ (MPOB, 2009). These oils are mixed together with other ingredients such as skimmed or whole milk powder, cocoa powder, sugar, salt, emulsifier and flavour. Chocolate spread is formulated to contain low amount of solids at room temperature. Due to this specification, the product correlates with oil separation as it contains significant amount of liquid oil (Shamsudin, 2004). El-kalyoubi et al. (2011) studied the effect of replacing palm oil in the conventional soft chocolate spread with palm olein and cottonseed oil. The study found that 25\% replacement of palm olein was the closest to the control sample in terms of rheological properties and this replacement was more acceptable by sensory evaluaters. Red palm olein was also used as confectionery fats in a study by El-Hadad et al.
(2011) as it contains $\beta$-carotene which has provitamin A functionality. In addition, Shamsudin et al. (2015) incorporated palm tocotrienol in the palmbased chocolate spread formulation to reduce lipid oxidation process which occurs during storage and thereby improving shelf-life of the product.

Ramli and Foo (2011) used palm olein in the formulation of chocolate syrup and studied its rheological properties. Chocolate syrup is normally used as ice cream and cake topping. Other ingredients in the chocolate syrup are water, sugar, cocoa powder, lecithin and vanilla flavour. The study found that the viscosity of the formulation was $14.62 \pm 1.97$ Pa.s $\left(4^{\circ} \mathrm{C}\right)$ and $3.91 \pm 0.21$ Pa.s $\left(25^{\circ} \mathrm{C}\right)$. Palm olein chocolate syrup was also preferred over a commercial syrup by the sensory panellists. Thus, this formulation has the potential to be used as chocolate syrup. Palm oil can also be used in ice cream coating formulations to replace the conventional lauric fats-based ice-cream coating that provides waxy problem (Cain et al., 1999). In addition, Biswas et al. (2017) had managed to produce confectionery fillings by using PMF, RBD palm kernel oil and RBD palm stearin with a ratio of 14.9:59.6:25.5, respectively. A review by Mat Dian et al. (1997) revealed that interesterified oils can be used to formulate CB-like fats. The interesterified oil blend of 25\% palm stearin and $75 \%$ palm kernel olein as well as an oil blend of $25 \%$ palm stearin, $37.5 \%$ palm kernel olein and $37.5 \%$ palm kernel oil were found suitable for cream filling formulation in biscuits.

\section{CONCLUSION}

Palm oil, palm kernel oil and their fractions are suitable for the production of confectionery fats as they are able to provide the required properties needed. PMF blended with other vegetable oils is the main palm oil fraction used for the production of CBE. Solid fraction of soft stearin obtained through two-stage fractionation has been shown to provide comparable properties with PMF. CBR that has low or zero trans is getting a lot of focus and demand nowadays. Such CBR can be produced with palm oil fractions with certain procedures during fractionation. Various individual blends that contain palm stearin or low lauric and myristic fractionated palm kernel oil and palm oil are examples of CBR with low or zero trans-fatty acid. Soft palm kernel stearin and hard palm kernel stearin are suitable for the formulation of CBS. Enzymatic modification has enhanced the use of palm oil and fractions as fats for the production of CBE and CBS. Various interesterified (IE) oils from PMF and RBD palm oil are suitable as CBE, whilst IE oils from palm stearin, palm kernel olein, palm kernel oil and PMF are suitable as CBS. In addition, palm oil and its 
fractions are also suitable for other confectionery applications such as soft chocolate, chocolate syrup, ice-cream coating and confectionery filling.

\section{ACKNOWLEDGEMENT}

The authors would like to thank the DirectorGeneral of MPOB for permission to publish this article.

\section{REFERENCES}

ABIGOR, R D; MARMER, $\mathrm{W}$ N; FOGLIA, $\mathrm{T}$ A; JONES, K C; DICICCIO, R J; ASHBY, R and UADIA, P O (2003). Production of cocoa butter-like fats by the lipase-catalysed interesterification of palm oil and hydrogenated soybean oil. J. Amer. Oil Chem. Soc., 80: 1193-1196.

AFOAKWA, E O (2016). Tempering and fat crystallization effects on chocolate quality. Chocolate Science and Technology. $2^{\text {nd }}$ Edition, John Wiley \& Sons Ltd. p. 536-550.

BISWAS, N; CHEOW, Y L; TAN, C P; KANAGARATNAM, S and SIOW, L F (2017). Cocoa butter substitute (CBS) produced from palm mid-fraction/palm kernel oil/palm stearin for confectionery fillings. J. Amer. Oil Chem. Soc., 94: 235-245.

BOOTELLO, $\mathrm{M}$ A; HARTEL, $\mathrm{R}$ W; GARCES, R; MATÍNEZ-FORCE, E and SALAS, J J (2012). Evaluation of high oleic-high staric sunflower hard stearins for cocoa butter equicalent formulation. Food Chemistry, 134: 1409-1417.

BOOTELLO, M A; HARTEL, R W; LEVIN, M; MARTINÉZ-BLANES, J; REAL, C; GARCES, R; MATÍNEZ-FORCE, E and SALAS, J J (2013). Studies of isothermal crystallisation kinetics of sunflower hard-stearin-based confectionery fats. Food Chemistry, 139: 184-195.

BORHAN, R H; SAID, M and MAT SAHRI, M (2011). Enzymatic interesterification of palm products for producing low calorie cocoa butter substitutes. J. Applied Science, 11: 3750-3754.

CAIN, F W; HUGHES, A D and SLANGER, H (1995). Non-hydrogenated coating fats. US patent, US5439700 A.

CAIN, F W; MANSON, H and NICOLAAS, J (1999). Ice-cream coating fats. US patent, US5939114 A.

CALLIAUW, G; FOUBERT, I; GREYT, W DE; DIJCKMANS, P; KELLENS, M and DEWETTINCK,
K (2005). Production of cocoa butter substitutes via two-stage static fractionation of palm kernel oil. J. Amer. Oil Chem. Soc., 82: 783-789.

CRUZ, A F; ALVAREZ, C A and TEAM FOOD COLOMBIA, S A (2015). Cocoa butter substitutes. US patent, US20150164102 A1.

DEFFENCE, E (1995). Dry multiple fractionation: trends in products and applications. Lipid Technology, 7: 34-38.

DOWNS, S M; THOW, A M and LEEDER, S R (2013). The effectiveness of policies for reducing dietary trans fat: a systematic review of the evidence. Bulletin World Health organization, 91: 262-269.

ELHAM, M; NAZANIN, V and RAMLI, N (2013). Physico-chemical properties and antioxidant activity of a synthetic cocoa butter equivalent obtained through modification of mango seed oil. International J. Food Science and Technology, 48: 15491555.

EL-HADAD, N N M; YOUSSEF, M; ABD EL-AAL, M $\mathrm{H}$ and ABOU-GHARBIA, $\mathrm{H} \mathrm{H}$ (2011). Utilisation of red palm olein in formulating functional chocolate spread. Food Chemistry, 124: 285-290.

EL-KALYOUBI, $\mathrm{M}$; $\quad$ KHALLAF, $\mathrm{M}$ F; ABDELRASHID, A and EMAN, M M (2011). Quality characteristic of chocolate-containing some fat replacer. Annals of Agricultural Science, 56(2): 89-96.

FIRMIN, M W; GILLETTE, A L; HOBBS, T E and WU, D I (2016). Effects of olfactory sense on chocolate craving. Appetite, 105: 700-704.

GEE, P T (2007). Analytical characteristics of crude and refined palm oil and fractions. European J. Lipid Science and Technology, 109(4): 373-379.

GUNSTONE, F D; HARWOOD, J L and PADLEY, F B (1992). The Lipid Handbook. London: Chapman and Hall. p. 57-60.

HASHIMOTO, S; NEZU, T; ARAKAWA, H; ITO, $T$ and MARUZENI, S (2001). Preparation of sharpmelting hard palm midfraction and its use as hard butter in chocolate. J. Amer Oil Chem. Soc., 78: 455460.

HOSSAIN, M B (2013). Applications of palm oil and palm kernel oil in different food products of Bangladesh. Daffodil International University J. Science and Technology. Vol. 8.

IDRIS, N A and SAMSUDIN, S (1995). Development of specialty fats for selected food. Paper presented 
at the National Seminar on Food Technology 1995, Kuala Lumpur.

IDRIS, NA and MATDIAN, NL(2005). Interesterified palm products as alternatives to hydrogenation. Asia Pacific J. Clinical Nutrition, 14: 396-401.

IDRIS, N A and MAT SAHRI, M (2007). Utilization of palm oil and palm products in shortenings and margarines. European J. Lipid Science and Technology, 109: 422-432.

JAHURUL, M H A; ZAIDUL, I S M; NIK NORULAINI, N A; SAHENA, F; ABEDIN, M Z; MOHAMED, A and MOHD OMAR, A K (2014). Hard cocoa butter replacers from mango seed fat and palm stearin. Food Chemistry, 154: 323-329.

JÁUREGUI-LOBERA， I; BOLAŃOS-RIOS, P; VALERO, E and PRIETO, I R (2012). Induction of food craving experience: the role of mental imagery, dietary restraint, mood and coping strategies. Nutricion Hospitalaria, 27: 1928-1935.

JUN, J; PEMBE, W; CE, Q; CONG, S; LIANG, J; DAN, $X$; JIANHUA, H; QINGZHE, J and XINGGUO, W (2016). Mango kernel fat based chocolate with heat resistant triacylglycerols: production via blending using mango kernel fat mid-fraction and palm midfractions produced in different fractionation paths. RSC Advances, 110: 108981-108988.

KANG, K K; KIM, S; KIM, I H; LEE, I H and KIM, B H (2003). Selective enrichment of symmetric monounsaturated triacylglycerols from palm stearin by double solvent fractionation. J. Food Science and Technology, 51: 242-252.

KANG, K K; JEON, H; KIM, I and KIM, B H (2013). Cocoa butter equivalents prepared by blending fractionated palm stearin and shea stearin. J. Food Science and Biotechnology, 22: 347-352.

KELLENS, M; GIBON, V; HENDRIX, $\mathrm{M}$ and DE GREYT, W (2007). Palm oil fractionation. European J. Lipid Science and Technology, 109: 336-349.

LIPP, M and ANKLAM, E (1998). Review of cocoa butter and alternative fats for use in chocolate. Food Chemistry, 62: 73-99.

MACDIARMID, J I and HETHERINGTON, M M (1995). Mood modulation by food: an exploration of affect and cravings in 'chocolate addicts'. British J. Clinical Psychology, 34: 129-138.

MPOB (2009). Pocketbook of Palm Oil Uses. $6^{\text {th }}$ Edition. MPOB, Bangi. p. 3-44.
MAT DIAN, N L; AFFANDI, $\mathrm{S}$ and ISMAIL, $\mathrm{R}$ (1997). Trans fatty acids free food formulation based on palm oil and its products. A review. PORIM Occasional Paper No. 36: 1-21.

MINIFIE, B W (2012). Cocoa butter and replacement fats. Chocolate, Cocoa \& Confectionery, Science $\mathcal{E}$ Technology. $3^{\text {rd }}$ Edition. AVI Publishing Company. p. $65-110$.

MOHAMED IBRAHIM, O (2013). Lipase-catalysed acidolysis of palm mid fraction oil with palmitic and stearic fatty acid mixture for production of cocoa butter equivalent. J. Applied Biochemistry and Biotechnology, 171: 655-666.

NESARETNAM, K and MOHD ALI, A R (1992). Engkabang (illipe)-an excellent component for cocoa butter equivalent fat. J. Science and Food and Agriculture, 60: 15-20.

NESARETNAM, K and TEAH, Y K (1990). Specialty fats from palm and palm kernel oils - a review of PORIM's activities. Palm Oil Developments No. 11: 1217.

NORIZZAH, A R; CHONG, C L; CHEOW, C $S$ and ZALIHA, O (2004). Effects of chemical interesterification on physiochemical properties of palm stearin and palm kernel olein blends. Food Chemistry, 86: 229-235.

ONG, A S H and GOH, S H (2002). Palm oil: a healthful and cost-effective dietary component. Food and Nutrition Bulletin, 23: 11-22.

PEASE, J J (1985). Confectionery fats from palm oil and lauric oil. J. Amer. Oil Chem. Soc., 62(2): 426-430.

RAMLI, N and FOO, S Y (2011). Effect of super olein and sunflower oil on the rheological properties of chocolate syrup. Sains Malaysiana, 40(4): 359-367.

RAMLI, N; SAID, M; AFTAR MIZAN, A B; TAN, Y and AYOB, M K (2014). Physico-chemical properties of blends of palm mid fraction, palm stearin and olive oil. J. Food Quality, 37: 57-62.

SAMSUDIN, S and RAHIM, M A A (1996). Use of palm mid-fraction in white chocolate formulation. J. Food Science and Food Agriculture, 71: 483-490.

SAMSUDIN, S; AFFANDI, $S$ and BURHANUDDIN, A S (1996). Palm-based chocolate pastel. PORIM Information Series No. 35.

SHAMSUDIN, S Y (2004). Trans-free palm-base chocolate spread. MPOB Information Series No. 251. 
SHAMSUDIN, S Y; ABD HAMID, $\mathrm{R}$ and KANAGARATNAM, S (2015). Chocolate spread with tocotrienols. MPOB Information Series No. 584 .

SHUKLA, V K S (2005). Cocoa butter, cocoa butter equivalents, and cocoa butter substitutes. Handbook of Functional Lipids. CRC Press. p. 279-307.

SMITH, K W (2001). Cocoa butter and cocoa butter equivalent. Structured and Modified Lipids (Gunstone, F D ed.). Marcel Dekker Inc. New York. p. 401-422.

SMITH, K W (2012). Confectionery fats. Cocoa Butter and Related Compounds. AOCS Press. p. 489.

SONWAI, S; KAPHUEAKNGAM, P and FLOOD, A (2014). Blending of mango kernel fat and palm oil mid-fraction to obtain cocoa butter equivalent. J. Food Science and Technology, 51: 2357-2369.

TALBOT, G (2007). Formulation and production of confectionery fats. Paper presented at the OFI Middle East 2007 Conference and Exhibition.
TIMMS, R E (2003). Properties, production and application. Confectionery Fats Handbook. The Oily Press. p. 229-325.

UAUY, R; ARO,A; CLARKE, R; GHAFOORUNISSA; L'ABBE, M; MOZAFFARIAN, D; SKEAFF, M; STENDER, S and TAVELLA, M (2009). WHO scientific updates on trans fatty acids: summary and conclusions. European J. Clinical Nutrition, 63: 68-75.

UNDURRAGA, D; MARKOVITS, A and ERAZO, S (2001). Cocoa butter equivalent through enzymatic interesterification of palm mid-fraction. Process Biochemistry, 36: 933-939.

WONG, S (1991). Some useful facts and findings on cocoa butter replacers and related informations. Specialty Fats versus Cocoa Butter. p. 101-317.

ZAIDUL, I S M; NORULAINI, N A; MOHD OMAR, A K and SMITH JR, R L (2007). Blending of supercritical carbon dioxide $\left(\mathrm{SC}-\mathrm{CO}_{2}\right)$ extracted of palm kernel oil fractions and palm oil to obtain cocoa butter replacer. J. Food Engineering, 78: 13971407. 